\title{
Chest Ultrasonography in Diagnosing Etiology of Acute Respiratory Failure
}

\section{Chiranjibi Pant, Anusmriti Pal, Manoj Yadav, Bishow Kumar Shrestha and Suraj Rana}

Department of Pulmonary, Critical Care and Sleep Medicine, Chitwan Medical College, Bharatpur, Chitwan, Nepal

\section{ABSTRACT}

Introduction: Lung ultrasonography (LUS) is a useful diagnostic tool in critical care setting. Lung ultrasound at bed side is relatively easy to perform, cost effective and reproducible. Analysis of various sign and profile, alone or in combination is as accurate as gold standard test like Computed Tomography scan of the chest in detection of etiology of acute respiratory failure. The aim of our study was to perform bed side lung ultrasound in patent with ARF and to find out the diagnostic accuracy of lung ultrasound when compared with diagnosis made by the clinician.

Methods: This descriptive observational study was conducted at tertiary care teaching centre in Nepal between February 2019 and July 2019. Consecutive samples of acute respiratory failure patient were included. Lung ultrasound was performed at bed side by fellows of pulmonary critical care medicine. Specific 10 signs of blue protocol were assessed in six different sites of both the chest. Findings of LUS was recorded and analysed to formulate a diagnosis, and finally compared with the final diagnosis.

Results: Forty eight patients of acute respiratory failure with median age of 66 years (17 to 89 years) were included with $66.7 \%$ being females. $97.9 \%$ of the patient presented with acute shortness of breath of less than one week duration. A total of 13 different diagnosis was made at the end of the treatment for all the patient. LUS accurately diagnosed them in 43 cases, with an overall accuracy of $89.6 \%$. Chronic obstructive pulmonary disease, pulmonary edema, pneumonia, pleural effusion, pneumothorax were accurately diagnosed with LUS however in acute respiratory distress syndrome and interstitial lung disease, lung ultrasound had poor diagnostic accuracy.

Conclusions: Lung ultrasound is useful tool in diagnosing etiology of acute respiratory failure. Diagnosis made by lung ultrasound was $89.6 \%$ correct when compared with final diagnosis made by clinician.

Key words: acute respiratory failure; critical care; lung ultrasound diagnosis

Correspondence: Chiranjibi Pant, Department of Pulmonary, Critical Care and Sleep Medicine, Chitwan Medical College, Bharatpur, Chitwan, Nepal. E-mail:chiranpant@gmail.com

DOI: http://dx.doi.org/10.3126/mjsbh.v19i1.26670

Submitted on: 2019-10-11

Accepted on: 2019-12-12 


\section{INTRODUCTION}

Acute Respiratory Failure (ARF) is a major cause of morbidity and mortality in Intensive Care Unit (ICU) admitted patient, where an urgent diagnosis is required to direct potentially life-saving therapy. ${ }^{1}$ Chest $x$ ray, Computed Tomography (CT) scan of the chest and Arterial Blood Gas (ABG) are the most widely used diagnostic tools in the management of such patients. Supine chest radiograph remains a cost-effective method for routine evaluation in ICU, but interpretation of the supine portable chest radiograph is a challenging issue. $^{2}$

CT scan is the gold standard examination for most pulmonary disease which is not always possible to perform in patients on ventillator, high inotropic support and critically ill status. ${ }^{3}$ Chest ultrasonography, on the other hand, enables a quick bedside examination of the patient, easily performed, cost effective and reproducible tool which can be helpful in such situations. ${ }^{4}$ Study done in use of lung ultrasound compared to chest radiograph for suspected pneumonia in Nepal shows better sensitivity than chest X-ray for the diagnosis of pneumonia. Given this diagnostic performance, lung ultrasound could be another imaging modality used to diagnose acute respiratory disease in a resource-limited setting. ${ }^{5}$

Our objective in this study was to diagnose the etiology of acute respiratory failure by lung ultrasound based on various signs described in "point of care lung ultrasound" the BLUE protocol and to compare LUS diagnosis with final diagnosis.

\section{METHODS}

This descriptive observational study was conducted in Medical Intensive Care Unit (MICU) of our hospital between February 2019 and July 2019. An ethical approval was taken from IRC prior to the study and all the patients enrolled in this study were pre-informed. Patients willing to participate in the study were explained about the nature of the study and informed written consent was obtained from them or from the relatives if patient is unable to give consent by himself / herself.
Consecutive samples of patients with acute respiratory failure admitted in MICU within the specific time period were enrolled. ARF was defined based on clinical symptoms and signs of hypoxemia with or without hypercapnia and arterial blood gases indicating very low oxygen tension $\left(\mathrm{PO}_{2}\right.$ less than $\left.60 \mathrm{mmHg}\right)$ with or without hypercapnia $\left(\mathrm{CO}_{2}\right.$ more than $\left.45 \mathrm{mmHg}\right)$ and low $\mathrm{Ph}^{6,7}$

All patients of ARF aged above 18 years, admitted in MICU were included. Patients with burn in anterior chest wall and post operative respiratory failure were excluded from the study .

Final diagnosis made by the MICU clinician was considered as a "gold standard". For the purpose of making clinical diagnosis i.e gold standard, they have used clinical evaluation, ABG, laboratory values and all possible imaging modalities except for lung ultrasound. Bed side lung ultrasound examination was done in MICU on day one of admission by a fellow of pulmonology and critical care. Sonosite ultrasound with curvilinear or phase array probes of 3 to $5 \mathrm{MHz}$ was used in a semirecumbent position, or supine if intubated. Six zones in each side of the lung were selected for lung ultrasound. These zones were demarcated by the anterior axillary, and posterior axillary lines and divided into upper and lower regions. Thus complete, bilateral examination include 12 zones. Findings of lung ultrasound were recorded in proforma as per ten sign mention on point of care lung ultrasound in "The BLUE Protocol". ${ }^{8}$ SPSS 20 software was used for data recording and analysis. For the purpose of this study, 95\% confidence interval was accepted as significant.

\section{RESULTS}

A total of 48 patients of ARF were enrolled in this study, median age of the patient was 66 years (17 to 89 years), of which $66.7 \%$ were females. Majority $(97.9 \%)$ presented with acute shortness of breath as their primary clinical complaint. Other complaints were fever in $50 \%$, cough $(25.0 \%)$ and chest pain $(20.8 \%)$ of the patient, The duration of illness was less than one week in $81.3 \%$ patients. 
Table 1. Comparison of LUS diagnoses with final ICU diagnoses with individual accuracies

\begin{tabular}{|c|c|c|c|}
\hline S.No. & $\begin{array}{l}\text { Final ICU } \\
\text { diagnosis } \\
(\mathrm{n}=48)\end{array}$ & $\begin{array}{l}\text { LUS diagnosis } \\
(\mathrm{n}=48)\end{array}$ & $\begin{array}{l}\text { Overall } \\
\text { accuracy }\end{array}$ \\
\hline 1 & $\begin{array}{l}\text { COPD-AE } \\
(n=15)\end{array}$ & $\begin{array}{l}\text { COPD-AE } \\
(\mathrm{n}=14) \\
\text { Fatal/Near fatal } \\
\text { asthma }(\mathrm{n}=1)\end{array}$ & $93.3 \%$ \\
\hline 2 & $\begin{array}{l}\text { ARDS } \\
(n=5)\end{array}$ & $\begin{array}{l}\text { ARDS }(n=3) \\
\text { Pulmonary } \\
\text { edema }(n=2)\end{array}$ & $60.0 \% *$ \\
\hline 3 & $\begin{array}{l}\text { ILD } \\
(n=3)\end{array}$ & $\begin{array}{l}\operatorname{ILD}(n=2) \\
\operatorname{ARDS}(n=1)\end{array}$ & $66.7 \%$ \\
\hline 4 & $\begin{array}{l}\text { Pulmonary } \\
\text { edema }(n=9)\end{array}$ & $\begin{array}{l}\text { Pulmonary } \\
\text { edema }(n=9)\end{array}$ & $100.0 \%$ \\
\hline 5 & $\begin{array}{l}\text { Pulmonary } \\
\text { embolism } \\
(n=1)\end{array}$ & $\begin{array}{l}\text { Pulmonary } \\
\text { embolism } \\
(n=1)\end{array}$ & $100.0 \%$ \\
\hline 6 & $\begin{array}{l}\text { Multilobar } \\
\text { pneumonia } \\
(n=5)\end{array}$ & $\begin{array}{l}\text { Multilobar } \\
\text { pneumonia } \\
(n=5)\end{array}$ & $100.0 \%$ \\
\hline 7 & $\begin{array}{l}\text { Pneumothorax } \\
(n=1)\end{array}$ & $\begin{array}{l}\text { Pneumothorax } \\
(n=1)\end{array}$ & $100.0 \%$ \\
\hline 8 & $\begin{array}{l}\text { Massive } \\
\text { pleural } \\
\text { effusion }(n=2)\end{array}$ & $\begin{array}{l}\text { Massive pleural } \\
\text { effusion }(n=2)\end{array}$ & $100.0 \%$ \\
\hline 9 & $\begin{array}{l}\text { Pneumonia } \\
\text { with } \\
\text { parapneumonic } \\
\text { effusion }(n=2)\end{array}$ & $\begin{array}{l}\text { Pneumonia with } \\
\text { parapneumonic } \\
\text { effusion }(n=2)\end{array}$ & $100.0 \%$ \\
\hline 10 & $\begin{array}{l}\text { ILD with } \\
\text { pneumonia } \\
(n=2)\end{array}$ & $\begin{array}{l}\text { ILD with } \\
\text { pneumonia } \\
(\mathrm{n}=1) \\
\text { ARDS }(\mathrm{n}=1)\end{array}$ & $50.0 \%$ \\
\hline 11 & $\begin{array}{l}\text { COPD-AE } \\
\text { with multilobar } \\
\text { pneumonia } \\
(\mathrm{n}=1)\end{array}$ & $\begin{array}{l}\text { COPD-AE with } \\
\text { multilobar } \\
\text { pneumonia } \\
(\mathrm{n}=1)\end{array}$ & $100.0 \%$ \\
\hline 12 & $\begin{array}{l}\text { Acute } \\
\text { respiratory } \\
\text { failure due to } \\
\text { sepsis/acidosis } \\
(n=1)\end{array}$ & $\begin{array}{l}\text { Acute } \\
\text { respiratory } \\
\text { failure due to } \\
\text { sepsis/acidosis } \\
(n=1)\end{array}$ & $100.0 \%$ \\
\hline 13 & $\begin{array}{l}\text { Fatal/near fatal } \\
\text { asthma }(\mathrm{n}=1)\end{array}$ & $\begin{array}{l}\text { Fatal/near fatal } \\
\text { asthma }(\mathrm{n}=1)\end{array}$ & $100.0 \%$ \\
\hline
\end{tabular}

Altogether, there were 13 different diagnoses made as final diagnoses $(n=48)$ by critical care physician (gold standard). LUS accurately diagnosed 43 cases, with an overall accuracy of $89.6 \%$. chronic obstructive pulmonary disease exacerbation
Table 2. Final diagnoses and individual LUS features

\begin{tabular}{|c|c|c|}
\hline S.No. & $\begin{array}{l}\text { Final ICU } \\
\text { diagnosis } \\
(\mathrm{n}=48)\end{array}$ & $\begin{array}{l}\text { LUS features } \\
\text { (Frequency) }\end{array}$ \\
\hline 1 & $\begin{array}{l}\text { COPD-AE } \\
(\mathrm{n}=15)\end{array}$ & $\begin{array}{l}\text { A lines only (10) } \\
\text { B lines (2) } \\
\text { A+B lines (2) } \\
\text { Quad sign, A+B lines (1) }\end{array}$ \\
\hline 2 & $\begin{array}{l}\text { ARDS } \\
(n=5)\end{array}$ & $\begin{array}{l}\text { B lines only (2) } \\
\text { B lines, Quad sign (1) } \\
\text { B lines, A+B lines, Shred } \\
\text { sign (2) }\end{array}$ \\
\hline 3 & $\begin{array}{l}\text { ILD } \\
(\mathrm{n}=3)\end{array}$ & $\begin{array}{l}\text { B lines, } A+B \text { lines }(2) \\
A+B \text { lines, Shred sign (1) }\end{array}$ \\
\hline 4 & $\begin{array}{l}\text { Pulmonary edema } \\
(\mathrm{n}=9)\end{array}$ & $\begin{array}{l}\text { B lines only (4) } \\
\text { B lines, A+B lines (1) } \\
\text { B lines, Jellyfish sign (1) } \\
\text { B lines, Quad sign (2) } \\
\text { B lines, Jellyfish sign, } \\
\text { Quad sign (1) }\end{array}$ \\
\hline 5 & $\begin{array}{l}\text { Pulmonary } \\
\text { embolism } \\
(\mathrm{n}=1)\end{array}$ & A lines only (1) \\
\hline 6 & $\begin{array}{l}\text { Multilobar } \\
\text { pneumonia } \\
(n=5)\end{array}$ & $\begin{array}{l}\text { A+B lines, Shred sign (3) } \\
\text { A+B lines, Shred sign, } \\
\text { Dynamic air } \\
\text { bronchogram (2) }\end{array}$ \\
\hline 7 & $\begin{array}{l}\text { Pneumothorax } \\
(n=1)\end{array}$ & $\begin{array}{l}\text { Barcode sign, Absent } \\
\text { lung sliding (1) }\end{array}$ \\
\hline 8 & $\begin{array}{l}\text { Massive pleural } \\
\text { effusion } \\
(n=2)\end{array}$ & $\begin{array}{l}\text { Jellyfish sign, Quad sign } \\
\text { (2) }\end{array}$ \\
\hline 9 & $\begin{array}{l}\text { Pneumonia with } \\
\text { parapneumonic } \\
\text { effusion } \\
(n=2)\end{array}$ & $\begin{array}{l}\text { A+B lines, Shred sign, } \\
\text { Quad sign }(2)\end{array}$ \\
\hline 10 & $\begin{array}{l}\text { ILD with } \\
\text { pneumonia } \\
(n=2)\end{array}$ & $\begin{array}{l}\text { B lines, Shred sign (1) } \\
\text { B lines, A+B lines, Shred } \\
\text { sign (1) }\end{array}$ \\
\hline 11 & $\begin{array}{l}\text { COPD-AE with } \\
\text { Multilobar } \\
\text { pneumonia } \\
(\mathrm{n}=1)\end{array}$ & $\begin{array}{l}\text { A lines, A+B lines, Shred } \\
\text { sign, Quad sign, Jellyfish } \\
\text { sign (1) }\end{array}$ \\
\hline 12 & $\begin{array}{l}\text { Acute respiratory } \\
\text { failure due to } \\
\text { sepsis/acidosis } \\
(n=1)\end{array}$ & A lines (1) \\
\hline 13 & $\begin{array}{l}\text { Fatal/near fatal } \\
\text { asthma } \\
(n=1)\end{array}$ & A lines only (1) \\
\hline
\end{tabular}

(COPD-AE), pneumonia, pulmonary edema, pleural effusion, pneumothorax was accurately 
diagnosed with LUS, where as, in five inaccurately diagnosed cases; two were ARDS, two were ILD and one was COPD-AE. These findings reflect that in patient with ARDS and ILD lung ultrasound has poor diagnostic accuracy. The different LUS diagnoses and their accuracies are presented in Table 1.

In analysis of LUS features of individual diagnosis, patient with COPD-AE $(\mathrm{n}=15)$ had a prominent $\mathrm{A}$ lines with normal lung slidings, where as in pulmonary edema most of the lung zone shows prominent B lines, associated with quad sign suggestive of pleural effusion. In ARDS $(n=5) B$ lines associated with shred sign, quad sign and $A B$ profile was seen. Pulmonary edema $(n=9)$ more frequent B lines and associated A+B Profile, Quad sign, Jellyfish sign was observed in few cases of cardiogenic pulmonary edema. In ILD $(n=3)$ combination of B lines, A+B lines, Shred sign were seen. One patient was diagnosed as pulmonary embolism, his LUS findings was presence of prominent A- lines and the patient had DVT (deep vein thrombosis) in lower limb ultrasound. In multilobar pneumonia $(n=5)$, Shred sign, dynamic air bronchogram and $\mathrm{A}+\mathrm{B}$ lines was observed. One patient had a pneumothorax absent lung sliding, Barcode sign was observed in that patient. Massive pleural effusion $(n=2)$ patient showed B lines, Jellyfish sign, Quad sign. In pneumonia with parapneumonic effusion ( $\mathrm{n}=2)$, Shred sign, Quad sign and $\mathrm{A}+\mathrm{B}$ lines were seen. In ILD with pneumonia $(n=2)$, our observation in lung ultrasound was presence of $\mathrm{B}$ lines in combination with Shred sign, and $\mathrm{A}+\mathrm{B}$ lines. In final clinical diagnosis of one patient COPD-AE with multilobar pneumonia $(n=1)$ combination of $A$ lines, $A+B$ lines, Shred sign, Quad sign, Jellyfish sign was observed. Similarly in fatal/near fatal asthma $(n=1)$ and acute respiratory failure due to sepsis/acidosis $(n=1)$ only A lines lines were visible with LUS. The LUS diagnoses and individual LUS features are presented in Table 2.

\section{DISCUSSION}

ARF is a common medical emergency with increasing incidence. ARF can be life threatening if not recognised and treated in time and majority of the conditions are related with lung pathology. The leading causes of ARF in young population are pneumonia, ARDS, sepsis, asthma, drug ingestion, and trauma. Similarly in elderly population, pneumonia, heart failure, COPD-AE, ARDS, and sepsis are common. ${ }^{9}$ Among 48 cases of acute respiratory failure, COPD-AE, pulmonary edema, ARDS, pneumonia was the common final diagnosis in our study. Final diagnosis of ARF was made based on clinician evaluation, $\mathrm{ABG}$, and radiological findings. 'Gold-standard' imaging HRCT of the chest was less frequently used to make diagnosis because it confer the risks of transport, ${ }^{10}$ in addition we have used bed side LUS to find out the etiology of ARF. When compared with final diagnosis, LUS diagnosis was $89.6 \%$ matched, which show LUS is equally efficient tool in making correct diagnosis at bed side. Our findings were consistent with study done by Lichtenstein DA et al. ${ }^{8}$

The two most common inaccurate diagnosis by LUS in our study were ARDS and ILD. LUS findings in ARDS patient had overlap features of pulmonary edema, pneumonia and effusion. ${ }^{11}$ multiple $B$ Lines, shred sign and $\mathrm{AB}$ profile alone or in combination were observed in our patient of ARDS. Since the stages of ARDS changes with time and treatment there is a possibility of variation in radiological findings. Similar overlaps were also noted in patient with ILD. Presence of such multiple additional features, time bound changes in disease pathological stages and associated duel pathology in these two cases could have resulted inaccuracy in LUS diagnosis. Falcetta A et al. ${ }^{12}$ have mentioned that B-lines, pleural irregularities and nodules or consolidations are seen in DPLD, however there is insufficient data to establish accuracy of LUS in diagnosis of interstitial lung disease in ARF. 13

Finally our study has few limitations as we know ultrasound is undeniably an operator-dependent imaging modality, as all the ultrasound performer in our study were non expert clinician there might be biasness in diagnostic accuracy. Although study conducted by Dexheimer Neto FL et al. concluded 
that LUS based on the BLUE protocol was reproducible by physicians who are not ultrasound experts and accurate for the diagnosis of pneumonia and pulmonary edema. ${ }^{14}$ Since all the fellow clinician who were performing LUS were not blinded to clinical information this may have influenced the accuracy in ultrasound diagnosis. In some of the diagnosis, the number of patients were too small to be significant like $1 / 2$ positive $(50 \%)$ or $1 / 1$ positive $(100 \%)$.

\section{CONCLUSIONS}

This study concluded that lung ultrasound is equally useful tool in assessment of etiology of acute respiratory failure, it has a diagnostic accuracy of $89.6 \%$. Since lung ultrasound is quick, reproducible and even can be done by non-expert intensivist at bed side it has to be incorporated in diagnosing etiology of ARF in critical care settings .

\section{ACKNOWLEDGEMENTS}

We are thankful to CMCTH, Bharatpur, Nepal for providing the platform to perform this study. The authors would also like to thank all the participants in this study and the MICU staffs for their help during the study.

To cite this article: Pant C, Pal A, Yadav M, Shrestha BK, Rana S. Chest ultrasonography in diagnosing etiology of acute respiratory failure. MJSBH. 2019;19(1):20-5.

Conflict of Interest: None declared

\section{REFERENCES}

1. Khilnani G, Bammigatti C. Acute Respiratory failure - Algorithmic Approach - Diagnosis and Management. Medicine update. 2005;547-52.

2. Daabis R, Banawan L, Rabea A, Elnakedy A, Sadek A. Relevance of chest sonography in the diagnosis of acute respiratory failure: comparison with current diagnostic tools in intensive care units. Egypt J Chest Dis Tuberc. 2014;63(4):979-85.

DOI: $10.1016 /$ j.ejcdt.2014.05.005

3. Waydhas C. Intrahospital transport of critically ill patients. Critical care. 1999;3(5):83-9.

DOI: $10.1186 / \operatorname{cc} 362$

4. Zanobetti M, Poggioni C, Pini R. Can chest ultrasonography replace standard chest radiography for evaluation of acute dyspnea in the ED? Chest. 2011;139(5):1140-7.

DOI: $10.1378 /$ chest.10-0435.

5. Amatya Y, Rupp J, Russell FM, Saunders J, Bales B, House DR. Diagnostic use of lung ultrasound compared to chest radiograph for suspected pneumonia in a resource-limited setting. Int J Emerg. 2018;11(1):8. DOI 10.1186/s12245-018-0170-2

6. Nadel JA, Murray JF, Mason R. Textbook of respiratory medicine: Saunders; 2000.

7. Goldman L, Schafer AI. Goldman-Cecil Medicine E-Book: Elsevier Health Sciences; 2015.

8. Lichtenstein DA, Meziere GA. Relevance of lung ultrasound in the diagnosis of acute respiratory failure: the BLUE protocol. Chest. 2008;134(1):117-25.

DOI: $10.1378 /$ chest.07-2800

9. Stefan MS, Shieh MS, Pekow PS, Rothberg MB, Steingrub JS, Lagu T, et al. Epidemiology and outcomes of acute respiratory failure in the United States, 2001 to 2009: a national survey. J Hosp Med. 2013;8(2):76-82.

DOI: $10.1002 / \mathrm{jhm} .2004$.

10. Waydhas C. Equipment review: Intrahospital transport of critically ill patients. Critical Care. 1999;3(5):83.

DOI: $10.1186 / \mathrm{cc} 362$. 
11. Copetti R, Soldati G, Copetti P. Chest sonography: a useful tool to differentiate acute cardiogenic pulmonary edema from acute respiratory distress syndrome. Cardiovascular ultrasound. 2008;6:16.

DOI: $10.1186 / 1476-7120-6-16$.

12. Falcetta A, Leccardi S, Testa E, Papaleo F, Fenoglio L, Melchio R. The role of lung ultrasound in the diagnosis of interstitial lung disease. Shanghai Chest. 2018;2(5).

Available from: http://shc.amegroups.com/article/view/4293.

13. Wallbridge P, Steinfort D, Tay TR, Irving L, Hew M. Diagnostic chest ultrasound for acute respiratory failure. Respir Med. 2018;141:26-36.

DOI: $10.1016 /$ j.rmed.2018.06.018

14. Dexheimer Neto FL, Andrade JM, Raupp AC, Townsend Rda S, Beltrami FG, Brisson H, et al. Diagnostic accuracy of the Bedside Lung Ultrasound in Emergency protocol for the diagnosis of acute respiratory failure in spontaneously breathing patients. J Bras Pneumol. 2015;41(1):58-64.

DOI: $10.1590 / \mathrm{s} 1806-37132015000100008$. 